Polymer Journal, Vol. 39, No. 2, pp. 118-128 (2007)

(C) 2006 The Society of Polymer Science, Japan

\title{
Comprehensive Sequence Distribution Analysis of Butyl methacrylate-Acrylonitrile Copolymers by Two-dimensional NMR Spectroscopy
}

\author{
Ajaib Singh BRAR ${ }^{\dagger}$ and Jaspreet KAUR \\ Department of Chemistry, Indian Institute of Technology-Delhi, New Delhi 110016, India
}

(Received August 24, 2006; Accepted October 27, 2006; Published December 14, 2006)

\begin{abstract}
The acrylonitrile-butyl methacrylate (A/B) copolymers were synthesized by solution polymerization utilizing 2,2'-azobisisobutyronitrile (AIBN) as free radical initiator. Reactivity ratios were assessed by KelenTudos and non-linear error in variable method and were found to $b e r_{A}=0.37 \pm 0.03, r_{B}=1.44 \pm 0.16($ KT) and $r_{A}=0.36, r_{B}=1.40($ RREVM) respectively which confirmed that butyl methacrylate monomer is more reactive than acrylonitirile towards propagating chain during radical polymerization. 2D HSQC spectroscopy in conjugation with TOCSY afforded explicit information about compositional and configurational sequences. Methine and $\beta$-methylene regions revealed compositional sensitivity up to pentad and tetrad level respectively with meso and racemic configurations. TOCSY demonstrated the coupling between the methine protons of A centered triad and pentad units with $\beta$-methylene protons of various tetrads. Heteronuclear multiple-bond correlation (HMBC) spectroscopy has been employed to study carbon (carbonyl/nitrile)-proton coupling. The carbonyl and nitrile carbons expressed compositional sensitivity up to the triad level. [doi:10.1295/polymj.PJ2006101]

KEY WORDS Solution Copolymerization / Acrylonitrile-Butyl methacrylate Copolymer / NMR /
\end{abstract}

Copolymerization is the most eminent and powerful method for introducing orderly changes in polymer properties. ${ }^{1}$ Synthetic polymers derived from functional methacrylates especially butyl methacrylate (BMA) has been widely used in industry, agriculture and medicine owing to their remarkable properties such as potential biocompatibility. ${ }^{2}$ Due to the low glass transition temperature and relatively poor mechanical properties, $\operatorname{poly}(n$-butyl methacrylate) is rarely used alone and in fact it more frequently plays a role as a modifier in polymer blends or it is copolymerized with others to obtain appropriate properties for various purposes. Copolymers of butyl methacrylate and its blends find various uses in coating and in biomedical materials for instance bone cement, ${ }^{3,4}$ bio-adhesives, ${ }^{5}$ bio-degradable matrices, ${ }^{5,6}$ controlled release drug delivery systems, ${ }^{7}$ humidity sensors. ${ }^{8}$

The elucidation of copolymer structure (copolymer composition, monomer sequence distribution) is of major concern for prediction of copolymer properties and to assess the correlation between structure and properties. NMR spectroscopy is a well established and powerful technique for determination of the sequence and the tacticity of monomers in polymers. ${ }^{9-22}$ In particular, 2D NMR spectroscopy has become a very important and invaluable technique for elucidating polymeric structure. HSQC and HMBC techniques provide correlations between ${ }^{1} \mathrm{H}$ and ${ }^{13} \mathrm{C}$ nuclei that are one-(HSQC), two- or three-(HMBC) bonds apart in polymeric chain and TOCSY renders correla- tion between protons in same spin system thus giving insights of various vicinal and geminal couplings. Consequently, it has become viable to assign an NMR spectrum "sequentially" by using 2D NMR spectra by means of homo- and hetero- correlation experiments. Hence, these 2D NMR experiments in conjugation with 1D technique furnish an efficient method for studying the microstructure of polymers. ${ }^{23-34}$

Lot of work has been reported in literature ${ }^{35-50}$ regarding acrylonitrile and alkyl methacrylate copolymers. Recently, Yeo et al. ${ }^{51}$ characterized acrylonitrile/methyl methacrylate copolymers by FT-IR, DSC, TGA, ${ }^{1} \mathrm{H}$ NMR and ${ }^{13} \mathrm{C}$ NMR. They also evaluated morphologies of these copolymers with electron microscopic studies. Here, we present the microstructural investigation and details of acrylonitrile-butyl methacrylate copolymers utilizing NMR techniques. In A/B (acrylonitrile-butyl methacrylate) copolymer $\alpha$-methyl, methine and methylene resonance regions were of immense interest and were unambiguously assigned using 2D-NMR (HSQC, TOCSY and HMBC) techniques which enabled the complete assignment of proton and carbon-13 resonances.

\section{EXPERIMENTAL}

\section{Materials}

Acrylonitrile (S.D. Fine-chem Ltd., India) and butyl methacrylate (Merck, Germany) were vacuum distilled and were stored in a freezer prior to being used.

†To whom correspondence should be addressed (Tel: +91-11-26591377, Fax: +91-11-25195693, E-mail: asbrar@chemistry.iitd.ernet.in). 
Table I. Copolymer composition of acrylonitrilebutyl methacrylate $(\mathrm{A} / \mathrm{B})$ copolymers

\begin{tabular}{ccc}
\hline $\begin{array}{c}\text { Feed mole } \\
\text { fraction }\left(\mathrm{f}_{\mathrm{A}}\right)\end{array}$ & $\begin{array}{c}\text { Percentage } \\
\text { conversion }\end{array}$ & $\begin{array}{c}\text { Copolymer } \\
\text { composition }\left(\mathrm{F}_{\mathrm{A}}\right)\end{array}$ \\
\hline 0.40 & 3.6 & 0.29 \\
0.55 & 4.2 & 0.39 \\
0.72 & 3.4 & 0.56 \\
0.84 & 2.4 & 0.70 \\
0.90 & 4.1 & 0.79 \\
\hline
\end{tabular}

The free radical initiator AIBN (GSC, India) was recrystallized from methanol, dried in a desiccator and stored in freezer until used.

\section{Polymerization}

A series of Acrylonitrile-Butyl methacrylate (A/B) copolymers, polyacrylonitrile and poly(butyl methacrylate) were prepared at $58^{\circ} \mathrm{C}$ by solution polymerization using AIBN $(0.05 \mathrm{~mol} \%)$ as initiator and DMF ( $N, N$-dimethylformamide; Qualigens, India) as solvent (Table I). The conversion was maintained below $10 \%$ by precipitating the copolymers in methanol; precipitate was dissolved in chloroform and subsequently the reprecipitation was carried out in excess of methanol. Finally, the copolymers were vacuum dried to constant weight.

\section{NMR Studies}

${ }^{1} \mathrm{H}$ and ${ }^{13} \mathrm{C}\left\{{ }^{1} \mathrm{H}\right\}$ NMR experiments were performed in $\mathrm{CDCl}_{3}$ (using TMS as a standard at $25^{\circ} \mathrm{C}$ ) or DMSO- $d_{6}$ (for PAN and $\mathrm{F}_{\mathrm{A}}=0.79$ at $90^{\circ} \mathrm{C}$ ) on Bruker $300 \mathrm{MHz}$ DPX spectrometer at frequency of $300.13 \mathrm{MHz}$ and $75.5 \mathrm{MHz}$, respectively. The quantitative ${ }^{13} \mathrm{C}\left\{{ }^{1} \mathrm{H}\right\}$ NMR experiments were carried out using the inverse-gated decoupling pulse program with $12 \mathrm{~s}$ as a delay time $\left(5 \mathrm{t}_{1}\right)$. All two-dimensional experiments were carried out on $300 \mathrm{MHz}$ DPX spectrometer having a dual probe. The pulse sequences 'invigpt' and 'inv4gplplrnd' of the bruker software were used to record gradient HSQC and HMBC experiments, respectively. A total of 32 scans were accumulated with a relaxation delay of $2 \mathrm{~s}$ for each of the 512/256 $\mathrm{t}_{1}$ experiments. The TOCSY experiment, with 32 scans being collected for each $t_{1}$ value, was carried out using standard pulse sequence. A total of 256 spectra each containing the $1 \mathrm{~K}$ data points were accumulated. ${ }^{52}$ Measurements were made on $5 \%(\mathrm{w} / \mathrm{v})$ polymer solution.

\section{RESULTS AND DISCUSSION}

\section{Reactivity Ratio and Copolymer Composition}

The copolymer compositions were ascertained from quantitative ${ }^{13} \mathrm{C}\left\{{ }^{1} \mathrm{H}\right\}$ NMR spectra by quantifying carbonyl and nitrile carbons. The mole fractions of acrylonitirile infeed $\left(\mathrm{f}_{\mathrm{A}}\right)$ and in copolymer $\left(\mathrm{F}_{\mathrm{A}}\right)$ are given in Table I. The values of reactivity ratio were determined employing Kelen-Tudos (KT) and non linear error in variable method (RREVM) and were found to be $\mathrm{r}_{\mathrm{A}}=0.37 \pm 0.03, \mathrm{r}_{\mathrm{B}}=1.44 \pm 0.16(\mathrm{KT})$ and $\mathrm{r}_{\mathrm{A}}=0.36, \mathrm{r}_{\mathrm{B}}=1.40(\mathrm{RREVM})$. These values match well with literature precedents ${ }^{46,53,54}$ and affirm that butyl methacrylate is more reactive than acrylonitirile towards propagating chain. Hence, the copolymer comprises of the larger portion of the butyl methacrylate in random placement. These values of reactivity ratio are comparable to those of other members of alkyl ${ }^{41-44,46}$ (methyl to hexyl and 2-hydroxy ethyl) methacrylate monomer series (when copolymerized with acrylonitirile monomer via free radical polymerization). Reactivity ratios, in principle, can assist in computing the theoretical triad fractions. It also provides a helping hand in estimation the composition of monomers in different copolymers, thus facilitating the assignment of various cross peaks in 2D NMR experiments.

\section{${ }^{13} C\left\{{ }^{1} H\right\}$ NMR Studies}

Figure 1 represents the completely assigned ${ }^{13} \mathrm{C}\left\{{ }^{1} \mathrm{H}\right\}$ NMR spectra of A/B $\left(\mathrm{F}_{\mathrm{A}}=0.39\right)$ copolymer. In this, the resonances of carbonyl, nitrile, $-\mathrm{OCH}_{2},{ }^{\mathrm{a}, \mathrm{b}} \mathrm{CH}_{2}$ and methyl carbons were observed in the same region as in the homopolymers. ${ }^{10,55}$ The quaternary and methylene carbon signals were broad and overlapped which were differentiated and recognized with the help of DEPT-135 (Figure 1). Especial emphasis was given to the resonances of methine, $\alpha$-methyl and methylene carbon which were rich in information about microstructure of copolymer.

\section{HSQC Studies}

Methine Region. Figure 2 depicts the expanded region of HSQC spectra assigned to the methine resonances. The methine carbon/proton resonances showed both stereochemical and compositional sensitivity. By comparing the HSQC spectrum of homopolymer (polyacrylonirile) with those of copolymers (A/B) of various composition, it was noticed that the methine region was further splitted and the spectral region 27.0-29.3/2.90-3.20, 24.3-27.0/2.40-2.90 and 21.5-24.0/2.25-2.75 ppm was understood to be due to the methine's carbon and proton correlation of $\mathrm{A}$ centered unit and were assigned to $\mathrm{AAA}, \mathrm{AAB}$ and $\mathrm{BAB}$ triads respectively. The spectral region attributed to AAA triad decreased in intensity as acrylonitrile content in the copolymer reduced. This triad region exhibited configurational sensitivity. Hence, crosspeaks (1), (2) and (3) were assigned to ArArA, ArAmA and AmAmA triads respectively. The AAB 


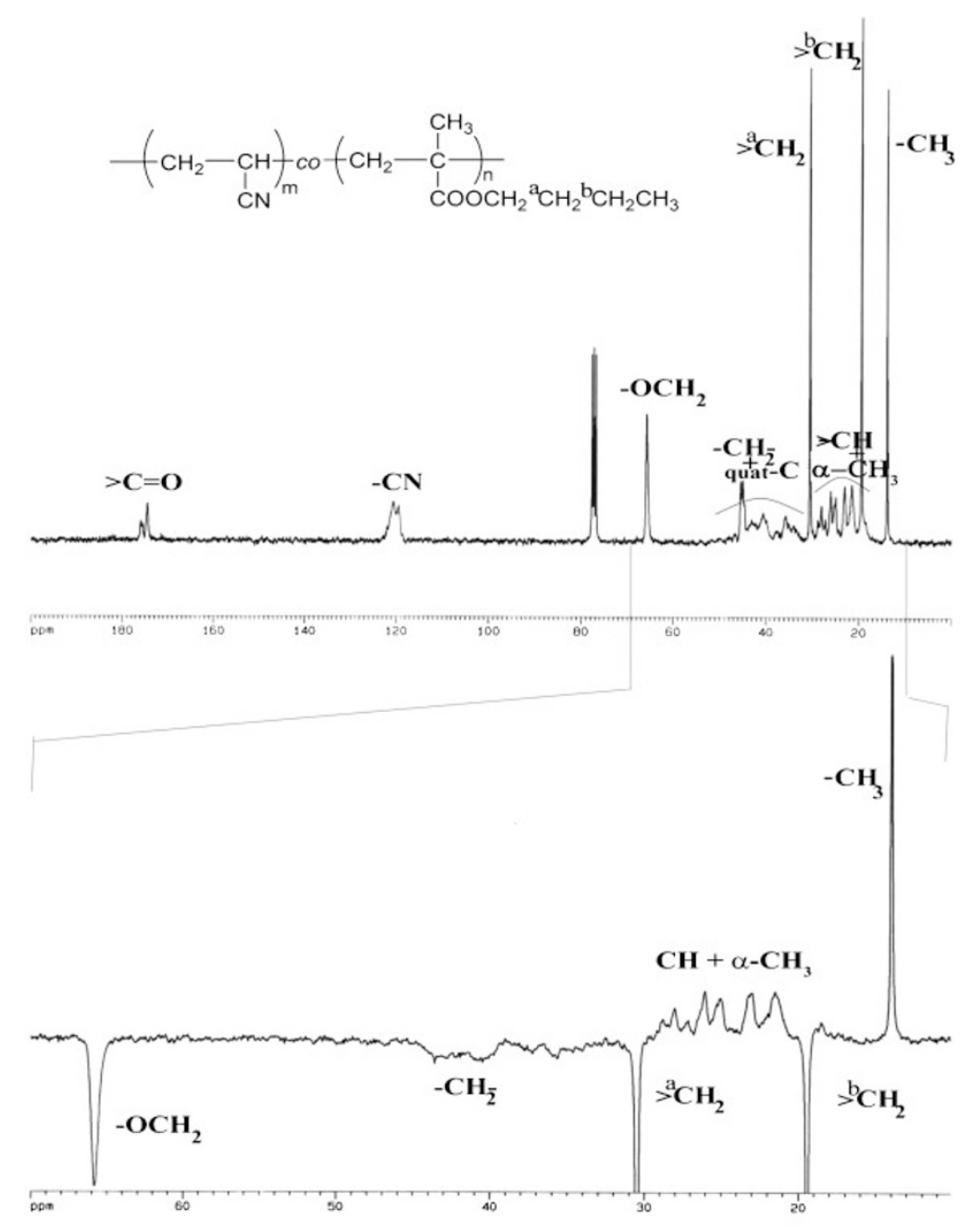

Figure 1. Fully assigned ${ }^{13} \mathrm{C}\left\{{ }^{1} \mathrm{H}\right\}$ NMR spectrum (up) and DEPT-135 NMR spectrum (down) of A/B copolymer $\left(\mathrm{F}_{\mathrm{A}}=0.39\right)$.

triad showed further compositional sensitivity and were assigned to AAABA (4), AAABB (5) and BAABB (6) pentad. Out of which AAABA and AAABB were configurationally sensitive. Thus, crosspeaks (a-f) were due to different stereo-chemical arrangements and were assigned accordingly given in Table II. These assignments were verified with the help of TOCSY, discussed in TOCSY section. Similarly, by comparing the HSQC spectra of A/B copolymer of different compositions, BAB triad was assigned up to pentad level. The crosspeaks (7), (8) and (9) were assigned to $\mathrm{ABABA}, \mathrm{ABABB}$ and $\mathrm{BBABB}$ pentad respectively. ABABA and ABABB pentad showed configurational sensitivity. So, the crosspeaks $(\mathrm{g}-\mathrm{j})$ were assigned to the recemic- and meso- configuration (Given in Table II).

$\beta$-Methylene Region. HSQC spectrum region ascribed to $\beta$-methylene correlation resonances in $\mathrm{A} / \mathrm{B}$ copolymer is shown in Figure 3. $\beta$-methylene spectral region around 46.00-55.00/1.20-2.27, 39.00-46.00/ 2.33-1.41 and 34.90-39.00/2.11-1.68 ppm were assigned to $\mathrm{BB}, \mathrm{AB}$, and $\mathrm{AA}$ dyads respectively. These assignments were done on the basis of alteration in intensity of contours with change in the copolymer composition and also equating these with that of polyacrylonitrile and poly(butyl methacrylate). These dyad regions showed further splitting due to compositional sensitivity (upto tetrad level) as well as configurational sensitivity. In BB dyad the crosspeaks along the carbon axis represents change in compostion and hence were assigned to BBBB, BBBA and ABBA tetrad. In all tetrad the crosspeaks along the proton axis were assigned to configurational sensitivity. Here, meso configuration can only give two cross peaks owing to the presence of two methylene protons in different environment where as racemic can account for single cross peak between two cross peaks due to meso configuration. The crosspeaks (10) and (12) were assigned to $\mathrm{H}_{\mathrm{a}}$ and $\mathrm{H}_{\mathrm{b}}$ protons of meso configuration while the racemic configuration resulted in peak (11). Similarly, the two crosspeaks (13), (15) were assigned to meso configuration, $\mathrm{BBmBA}\left(\mathrm{H}_{\mathrm{a}}\right), \mathrm{BBmBA}$ $\left(\mathrm{H}_{\mathrm{b}}\right)$ and that at (14) was due to racemic configurational sequence, BBrBA. ABBA tetrad showed con- 


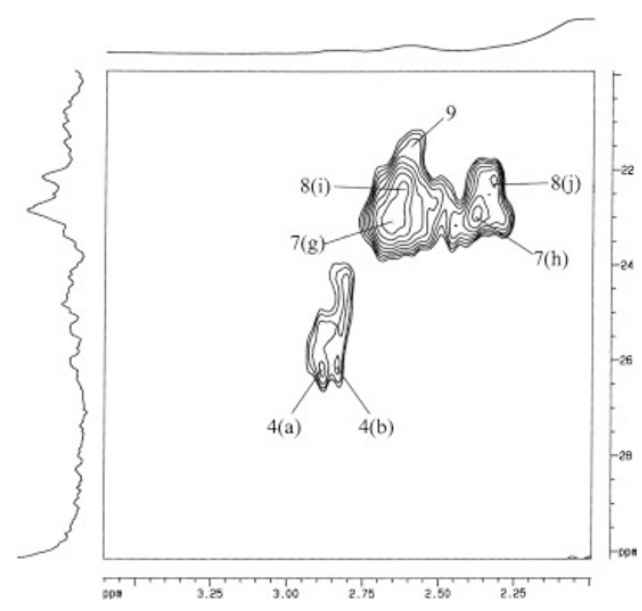

(a)

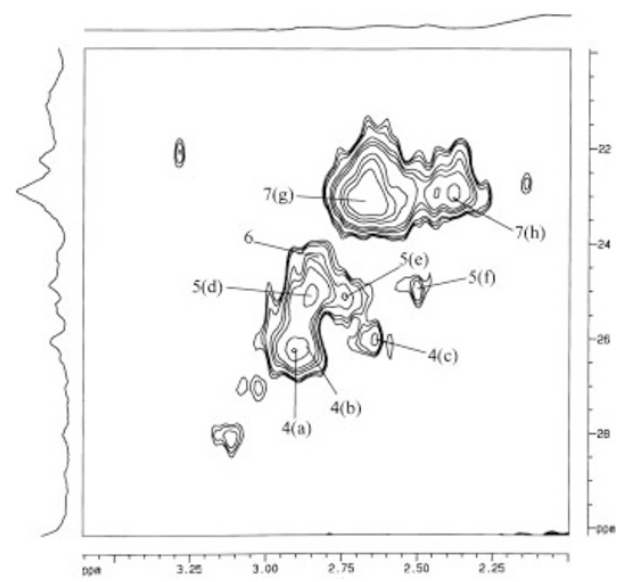

(b)

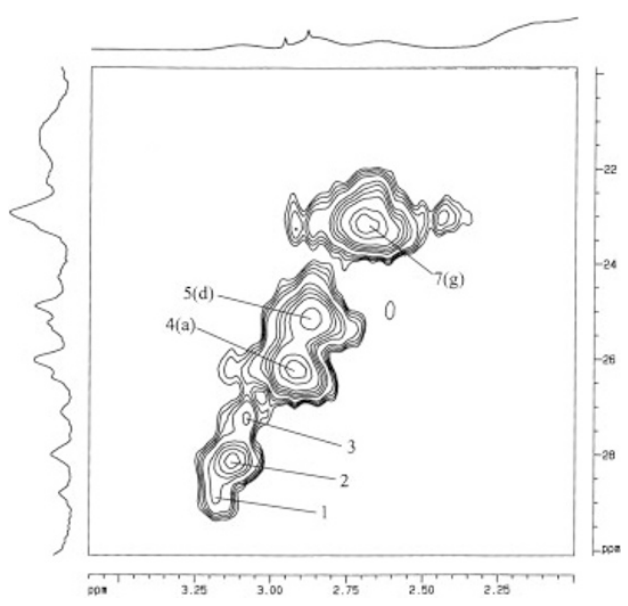

(c)

Figure 2. 2D HSQC NMR spectra of A/B copolymer showing the methine region, having (a) $\mathrm{F}_{\mathrm{A}}=0.29$, (b) $\mathrm{F}_{\mathrm{A}}=0.39$ and (c) $\mathrm{F}_{\mathrm{A}}=0.56$.

figurational sensitivity consequently the crosspeaks (16), (17) and (18) along the proton axis were assigned to $\mathrm{ABmBA}\left(\mathrm{H}_{\mathrm{a}}\right), \mathrm{ABrBA}$, and $\mathrm{ABmBA}\left(\mathrm{H}_{\mathrm{b}}\right)$ tetrad respectively. These assignments were further confirmed by two bond coupling in TOCSY between $\mathrm{H}_{\mathrm{a}}$ and $\mathrm{H}_{\mathrm{b}}$ (discoursed in TOCSY section). Accord-

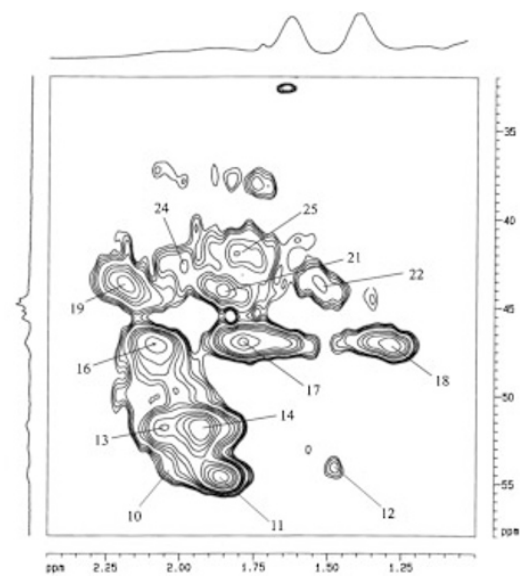

(a)

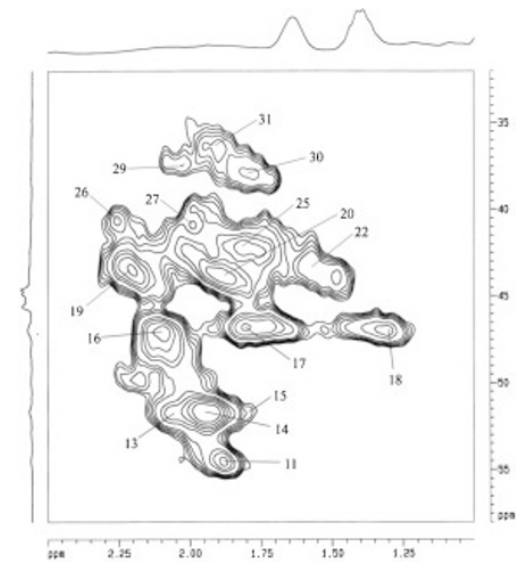

(b)

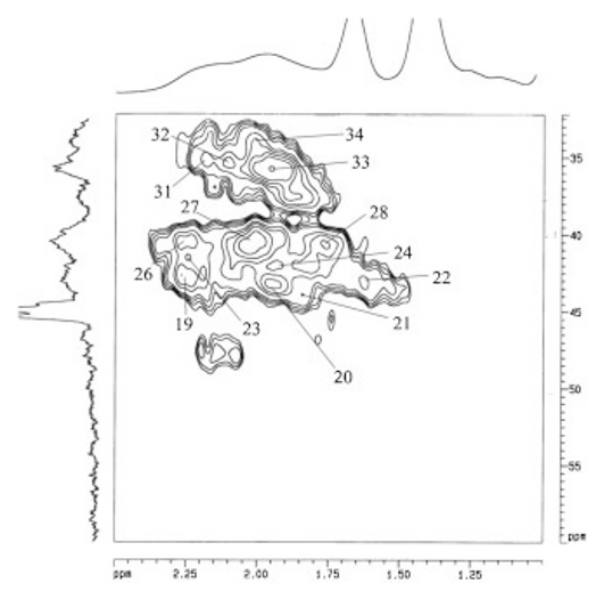

(c)

Figure 3. 2D HSQC NMR spectra of A/B copolymer showing the backbone methylene region, having (a) $F_{A}=0.29$, (b) $\mathrm{F}_{\mathrm{A}}=0.39$ and (c) $\mathrm{F}_{\mathrm{A}}=0.56$.

ingly, in $\mathrm{AB}$ dyads, splitting along carbon axis were assigned to tetrad compositional sequences and that each tetrad showed four cross peaks along proton axis were assigned to configurational sequences. As, the meso configuration can give two cross peaks because of the two methylene protons located in different environment and racemic also can account for two cross 
Table II. Spectral assignment of methine region (based on 2D HSQC and TOCSY studies)

\begin{tabular}{|c|c|c|c|c|c|}
\hline \multicolumn{3}{|c|}{ HSQC Assignments } & \multicolumn{3}{|c|}{$\begin{array}{l}\text { (Coupling between methine and methylene } \\
\text { protons analyzed by TOCSY spectral } \\
\text { analysis) }\end{array}$} \\
\hline $\begin{array}{l}\text { Methine } \\
\text { proton }\end{array}$ & $\begin{array}{l}\text { Cross } \\
\text { peak }\end{array}$ & $\begin{array}{c}\text { Peak value } \\
{ }^{13} \mathrm{C} /{ }^{1} \mathrm{H}(\mathrm{ppm})\end{array}$ & $\begin{array}{l}\text { Methylene } \\
\text { protons }\end{array}$ & $\begin{array}{l}\text { Cross } \\
\text { peak }\end{array}$ & $\begin{array}{c}\text { Peakvalue } \\
{ }^{1} \mathrm{H} /{ }^{1} \mathrm{H}(\mathrm{ppm})\end{array}$ \\
\hline ArArA & 1 & $28.71 / 3.18$ & ArA & 2 & $3.18 / 1.99$ \\
\hline AAA & 2 & $28.52 / 3.12$ & $\operatorname{AmA}\left(\mathrm{H}_{\mathrm{b}}\right)$ & 3 & $3.12 / 1.94$ \\
\hline AAA & 3 & $27.51 / 3.09$ & $\operatorname{AmA}\left(\mathrm{H}_{\mathrm{a}}\right)$ & 1 & $3.09 / 2.16$ \\
\hline AArABA & $4 a$ & $26.04 / 2.90$ & $\mathrm{AArAB}$ & 6 & $2.89 / 1.90$ \\
\hline AAmABA & $4 b$ & $26.00 / 2.86$ & $\operatorname{AAmAB}\left(\mathrm{H}_{\mathrm{a}}\right)$ & 4 & $2.87 / 2.20$ \\
\hline \multirow[t]{2}{*}{ AArAmBA } & $4 \mathrm{c}$ & $25.54 / 2.66$ & $\operatorname{AAmBA}\left(\mathrm{H}_{\mathrm{a}}\right)$ & 8 & $2.67 / 2.24$ \\
\hline & & & $\mathrm{AArAB}$ & 10 & $2.66 / 2.11$ \\
\hline AArABB & $5 \mathrm{~d}$ & $25.02 / 2.86$ & $\mathrm{AArAB}$ & 5 & $2.86 / 2.12$ \\
\hline AAABB & $5 \mathrm{e}$ & $25.02 / 2.74$ & & & \\
\hline AAABB & $5 f$ & $24.96 / 2.52$ & & & \\
\hline BAmABB & 6 & $24.41 / 2.86$ & BAAB & 7 & $2.86 / 1.76$ \\
\hline ABABA & $7 \mathrm{~g}$ & $23.02 / 2.68$ & & & \\
\hline $\mathrm{ABmABA}$ & $7 \mathrm{~h}$ & $22.98 / 2.35$ & $\operatorname{ABmAB}\left(\mathrm{H}_{\mathrm{b}}\right)$ & 12 & $2.34 / 1.82$ \\
\hline BBABA & $8 \mathrm{i}$ & $22.69 / 2.64$ & & & \\
\hline \multirow[t]{2}{*}{ BbmAmBA } & $8 j$ & $22.49 / 2.33$ & $\operatorname{BAmBB}\left(\mathrm{H}_{\mathrm{b}}\right)$ & 9 & $2.34 / 1.59$ \\
\hline & & & $\mathrm{ABmAB} / \mathrm{AAmBB}\left(\mathrm{H}_{\mathrm{b}}\right)$ & 12 & $2.34 / 1.82$ \\
\hline \multirow[t]{6}{*}{$\mathrm{BBrABB}$} & 9 & $21.30 / 2.56$ & $\mathrm{BArBB}\left(\mathrm{H}_{\mathrm{a}^{\prime}}\right)$ & 13 & $2.56 / 1.94$ \\
\hline & & & \multicolumn{3}{|c|}{$\begin{array}{l}\text { Geminal coupling between } H_{\mathrm{a}} \text { and } H_{\mathrm{b}} \\
\text { protons of } \beta-\mathrm{CH}_{2}\end{array}$} \\
\hline & & & AAmBB & 14 & $2.25 / 1.84$ \\
\hline & & & BAmBB & 15 & $2.23 / 1.65$ \\
\hline & & & AAmBA & 16 & $2.23 / 1.75$ \\
\hline & & & ABmBA & 17 & $2.10 / 1.34$ \\
\hline
\end{tabular}

peaks (in between two crosspeaks corresponding to meso configuration) because of the two protons of the methylene are not equivalent owing to the different environment of acrylonitrile and butyl methacrylate side chain groups. For this reason, the two crosspeaks (19) and (22) were recognized due to meso configuration, BAmBB $\left(\mathrm{H}_{\mathrm{a}}\right.$ and $\left.\mathrm{H}_{\mathrm{b}}\right)$ and that at (20) 43.54/1.94 and (21) $44.00 / 1.83$ due to racemic configuration, BArBB. Similarly, the crosspeaks (23), (25) were assigned to $A A m B B / A B m A B$ and (26), (28) to meso configuration in AAmBA tetrad for $\mathrm{H}_{\mathrm{a}}$ and $\mathrm{H}_{\mathrm{b}}$ respectively. The crosspeaks (24) and (27) were attributed to $\mathrm{AArBB} / \mathrm{ABrAB}$ and $\mathrm{AArBA}$ respectively. As already mentioned these assignments were established by the $\mathrm{H}_{\mathrm{a}}$ and $\mathrm{H}_{\mathrm{b}}$ coupling in TOCSY experiment.

In AA dyad the three cross peaks along carbon axis were assigned to compositional sequences, $\mathrm{BAAB}$ $(29,30)$, BAAA (31-33) and AAAA (34). These cross peaks along the carbon axis further showed configuration sensitivity along the proton axis. The two cross peaks were due to the meso configuration while one cross peak, between meso sequences was assigned to the racemic configuration. Therefore, the cross peaks (29) and (30) were assigned to BAAB tetrad in differ- ent configuration. Cross peaks (31) and (33) were due to $\mathrm{H}_{\mathrm{a}}$ and $\mathrm{H}_{\mathrm{b}}$ proton while (32) cross peak was appreciated to be due to racemic configuration. All assignments discussed in this section are consolidated in the tabular form in Table III.

$\alpha$-Methyl Region. The complexity and overlapping of signals encountered in the $\alpha$-methyl region of ${ }^{13} \mathrm{C}\left\{{ }^{1} \mathrm{H}\right\}$ spectra was resolved by employing 2DHSQC technique. 2D-HSQC spectral region assigned to $\alpha$-methyl of different copolymers possessing different composition of A/B are shown in Figure 4. The crosspeak 35 was assigned to $\mathrm{BBrBrBB}$ pentad on the basis of comparison of these spectra with that of poly(butyl methacrylate). On analyzing the variation in intensity of crosspeak with copolymer composition, the crosspeaks 36 and 37 were assigned to $\mathrm{ABrBrBB}$ and $\mathrm{ABrBrBA}$ pentads, respectively. It could be easily rationalized that incorporation of $\mathrm{A}$ unit increase the chemical shifts of $\alpha$-methyl carbons. On this basis further assignments were done which are listed in Table III. The BmBmB triad was assigned to the cross peak 39. BBA triad showed cross peak 40 and 41 . The three cross peaks $42-44$ were observed due to ABA triad (Given in Table III). 
Table III. The compositional and configurational assignments in A/B copolymers using 2D-HSQC NMR spectra

\begin{tabular}{|c|c|c|c|}
\hline Peak no. & ${ }^{13} \mathrm{C}(\mathrm{ppm})$ & ${ }^{1} \mathrm{H}(\mathrm{ppm})$ & Assignments \\
\hline & & & $\beta-\mathrm{CH}_{2}$ \\
\hline 10 & 54.62 & 2.04 & $\operatorname{BBmBB}\left(\mathrm{H}_{\mathrm{a}}\right)$ \\
\hline 11 & 54.84 & 1.86 & $\mathrm{BBrBB}$ \\
\hline 12 & 54.28 & 1.47 & $\operatorname{BBmBB}\left(\mathrm{H}_{\mathrm{b}}\right)$ \\
\hline 13 & 51.66 & 2.09 & $\operatorname{ABmBB}\left(\mathrm{H}_{\mathrm{a}}\right)$ \\
\hline 14 & 51.66 & 1.94 & $\mathrm{ABrBB}$ \\
\hline 15 & 51.67 & 1.80 & $\operatorname{ABmBB}\left(\mathrm{H}_{\mathrm{b}}\right)$ \\
\hline 16 & 46.79 & 2.09 & $\operatorname{ABmBA}\left(\mathrm{H}_{\mathrm{a}}\right)$ \\
\hline 17 & 46.78 & 1.80 & $\mathrm{ABrBA}$ \\
\hline 18 & 46.82 & 1.30 & $\operatorname{ABmBA}\left(\mathrm{H}_{\mathrm{b}}\right)$ \\
\hline 19 & 43.57 & 2.21 & $\operatorname{BAmBB}\left(\mathrm{H}_{\mathrm{a}}\right)$ \\
\hline 20 & 43.54 & 1.94 & $\operatorname{BArBB}\left(\mathrm{H}_{\mathrm{a}^{\prime}}\right)$ \\
\hline 21 & 44.00 & 1.83 & $\operatorname{BArBB}\left(\mathrm{H}_{\mathrm{b}^{\prime}}\right)$ \\
\hline 22 & 43.50 & 1.61 & $\operatorname{BAmBB}\left(\mathrm{H}_{\mathrm{b}}\right)$ \\
\hline 23 & 42.04 & 2.24 & $\mathrm{AAmBB} / \mathrm{ABmAB}\left(\mathrm{H}_{\mathrm{a}}\right)$ \\
\hline 24 & 42.07 & 1.92 & $\mathrm{AArBB} / \mathrm{ABr} \mathrm{AB}$ \\
\hline 25 & 42.08 & 1.82 & $\mathrm{AAmBB} / \mathrm{ABmAB}\left(\mathrm{H}_{\mathrm{b}}\right)$ \\
\hline 26 & 40.70 & 2.26 & $\operatorname{AAmBA}\left(\mathrm{H}_{\mathrm{a}}\right)$ \\
\hline 27 & 40.89 & 2.03 & AArBA \\
\hline 28 & 40.51 & 1.76 & $\operatorname{AAmBA}\left(\mathrm{H}_{\mathrm{b}}\right)$ \\
\hline 29 & 37.40 & 2.10 & BAAB \\
\hline 30 & 37.60 & 1.75 & BAAB \\
\hline 31 & 35.40 & 2.18 & $\operatorname{AAmAB}\left(\mathrm{H}_{\mathrm{a}}\right)$ \\
\hline 32 & 35.40 & 2.10 & $\mathrm{AArAB}$ \\
\hline 33 & 35.50 & 1.95 & $\operatorname{AAmAB}\left(\mathrm{H}_{\mathrm{b}}\right)$ \\
\hline \multirow[t]{2}{*}{34} & 33.50 & 2.16 & AAAA \\
\hline & & & $\alpha-\mathrm{CH}_{3}$ \\
\hline 35 & 16.89 & 0.89 & $\mathrm{BBrBrBB}$ \\
\hline 36 & 16.91 & 0.92 & $\mathrm{ABrBrBB}$ \\
\hline 37 & 17.50 & 0.96 & $\mathrm{ABrBrBA}$ \\
\hline 38 & 18.12 & 1.05 & $\mathrm{BmBrB}$ \\
\hline 39 & 21.31 & 1.24 & $\mathrm{BmBmB}$ \\
\hline 40 & 18.45 & 1.10 & BBA \\
\hline 41 & 18.60 & 1.19 & BBA \\
\hline 42 & 19.43 & 1.24 & $\mathrm{ABA}$ \\
\hline 43 & 24.59 & 1.33 & $\mathrm{ABA}$ \\
\hline 44 & 22.84 & 1.41 & $\mathrm{ABA}$ \\
\hline
\end{tabular}

\section{${ }^{1} H$ NMR and TOCSY Studies}

Once ${ }^{13} \mathrm{C}\left\{{ }^{1} \mathrm{H}\right\}$ NMR spectrum was assigned completely, various broad and overlapped resonances in ${ }^{1} \mathrm{H}$ NMR spectrum were assigned on the basis of one to one correlation between carbon and proton established with the help of 2D-HSQC NMR spectroscopy. The proton spectrum along with complete set of assignments is shown in Figure 5.

In order to comprehend the connectivity and to ascertain various couplings in the copolymer chain the TOCSY spectra were recorded and assignments were done. Two and three bond coupling between protons of different groups that are directly coupled in A/B copolymer can be seen in TOCSY experiment at low mixing time $(4 \mathrm{~ms}$ ) (shown in Figure 6$)$. The methine

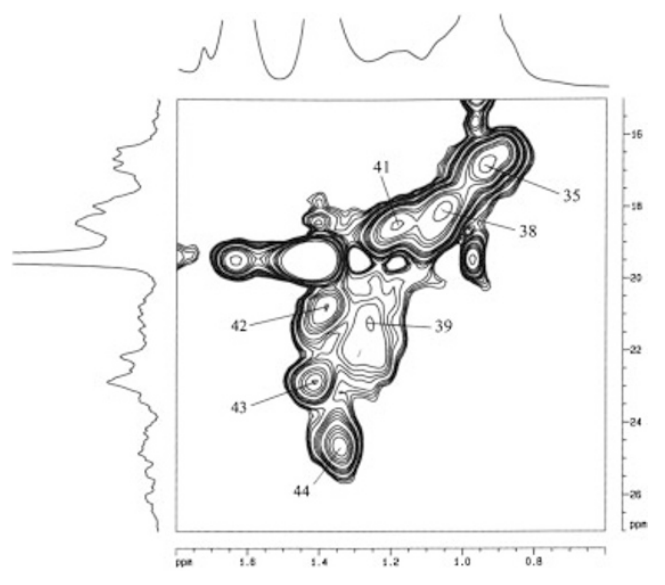

(a)

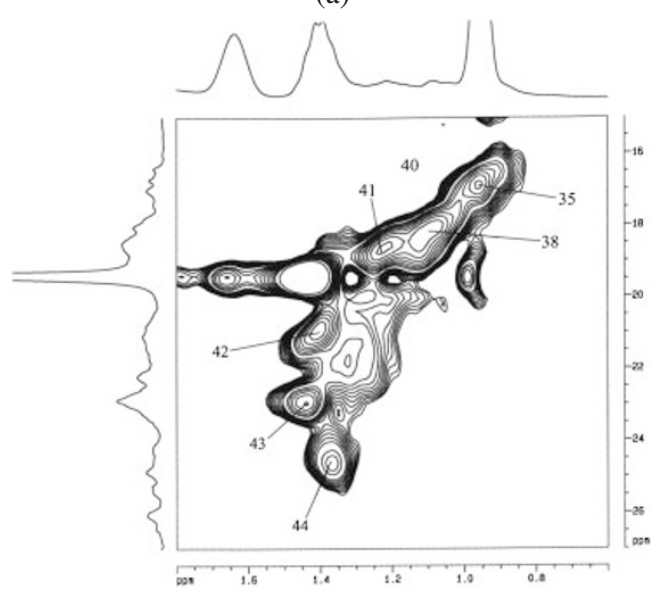

(b)

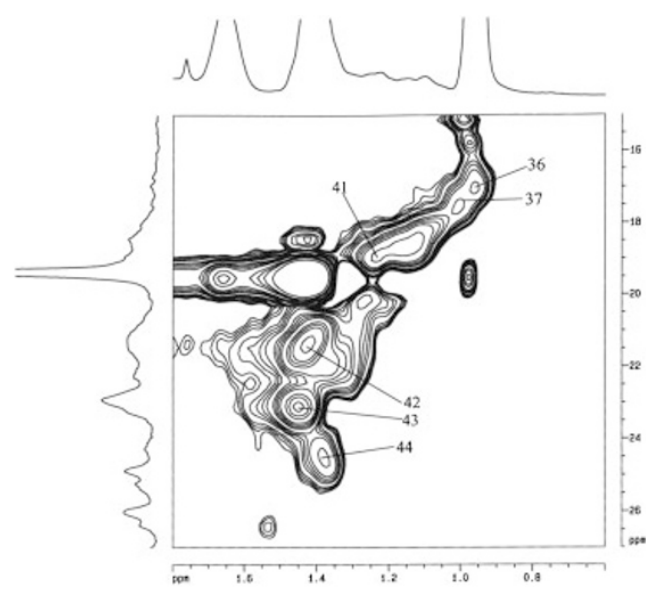

(c)

Figure 4. 2D HSQC NMR spectra of A/B copolymer showing the $\alpha$-methyl region, having (a) $\mathrm{F}_{\mathrm{A}}=0.29$, (b) $\mathrm{F}_{\mathrm{A}}=0.39$ and (c) $\mathrm{F}_{\mathrm{A}}=0.56$.

protons in various triads and pentads exhibited threebond coupling with the methylene protons of various dyads and tetrads. Crosspeaks (1-3) demonstrate coupling between the methine protons of AAA triad with $\beta$-methylene protons of AA tetrad. This assignment was accomplished by comparing various spectra of different copolymers of varying $\mathrm{A} / \mathrm{B}$ composition 


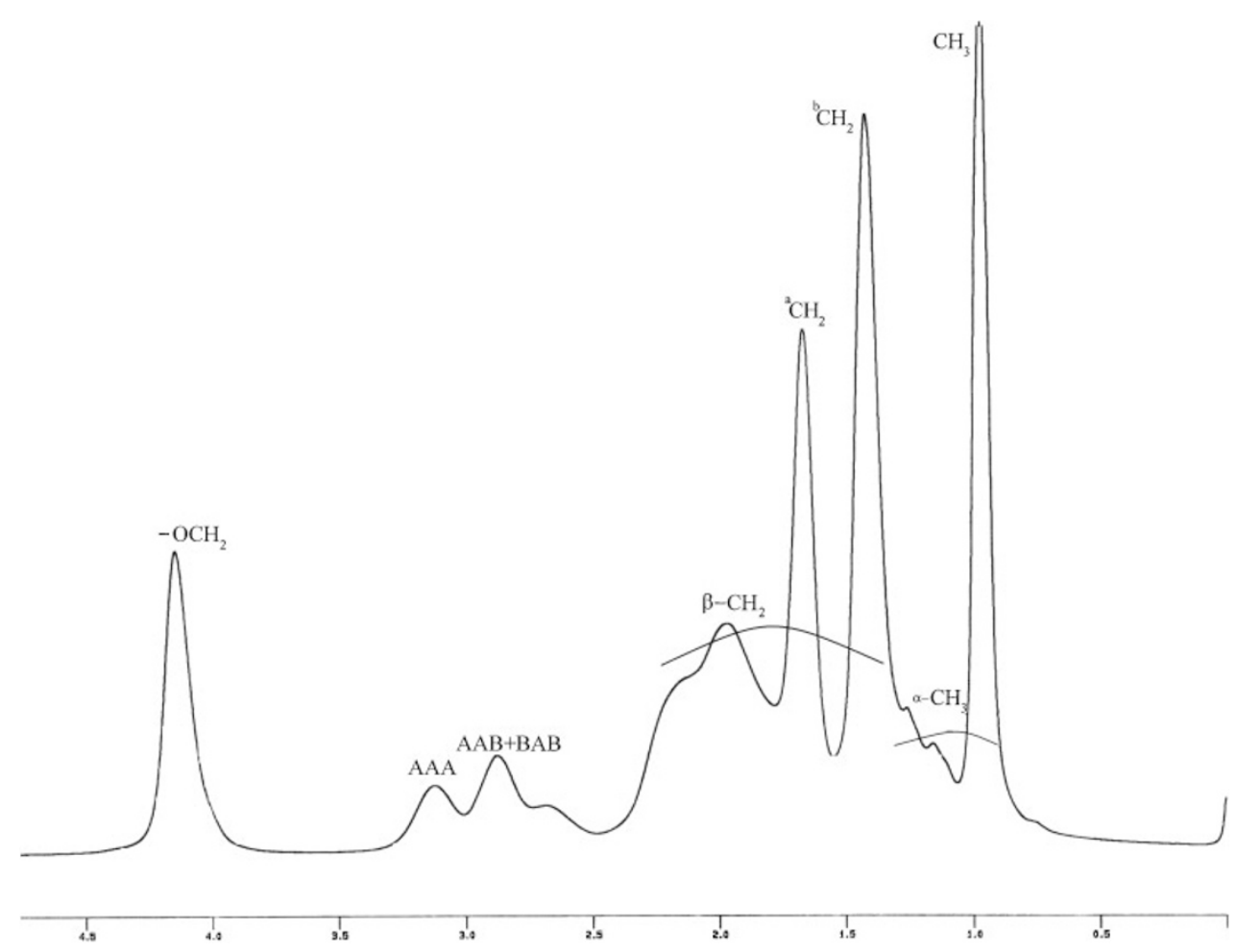

Figure 5. Assigned ${ }^{1} \mathrm{H}$ NMR spectrum of $\mathrm{A} / \mathrm{B}$ copolymer having $\mathrm{F}_{\mathrm{A}}=0.56$.

with TOCSY and HSQC spectra of poly(acrylonitrile). Methine proton in AAABA pentad revealed vicinal coupling with the $\beta$-methylene protons of $\operatorname{AAmAB}\left(\mathrm{H}_{\mathrm{a}}\right)$ (4), AArAB (6) and AAmBA $\left(\mathrm{H}_{\mathrm{a}}\right)$ (8). Crosspeaks (5) and (7) exhibited the coupling between $\beta$-methylene protons of $\mathrm{AArAB}$ and $\mathrm{BAmAB}$ $\left(\mathrm{H}_{\mathrm{b}}\right)$ tetrad and methine proton of $\mathrm{AAABB}$ and BAABB. Crosspeaks (9), (10), (12) and (19) rendered coupling information between methine proton of $\mathrm{ABABB}$ pentad and the $\beta$-methylene protons of $\mathrm{ABrAB} / \mathrm{AArBB}, \mathrm{AArAB}, \mathrm{ABmAB} / \mathrm{AAmBB}\left(\mathrm{H}_{\mathrm{b}}\right)$ and $\mathrm{BAmBB}\left(\mathrm{H}_{\mathrm{b}}\right)$ tetrads respectively. BBABB methine proton couples to $\mathrm{H}_{\mathrm{b}}$ of $\beta$-methylene proton in BAmAB tetrad.

Five crosspeaks (14-18) were due to the ${ }^{2} \mathbf{J}$ coupling of two nonequivalent protons $\mathrm{H}_{\mathrm{a}}$ and $\mathrm{H}_{\mathrm{b}}$ of $\beta$ methylene in AAmBB/ABmAB, BAmBB, AAmBA, $\mathrm{ABmBA}$ and $\mathrm{BAmAB}$ tetrads respectively (Table II, Figure 6c(i)).

The TOCSY spectrum, recorded at shorter mixing time, provides a view of direct couplings (AM spin type) whereas at higher mixing time it offers a perspective of relay coupling (AMX spin type) through magnetization transfer. The higher order sequences in the $\mathrm{A} / \mathrm{M}$ copolymers were assigned with the help of the higher mixing time TOCSY $(80 \mathrm{~ms})$ spectrum (Figure 7). The cross peak at (1') $\delta 3.05 / 2.87 \mathrm{ppm}$ revealed a relayed coupling between the methine protons of AAA and AAB triads, thus accounting for AAAB tetrad.

\section{HMBC NMR Studies}

Heteronuclear multiple-bond correlation (HMBC) spectroscopy involves proton-carbon connectivities through coupling over two or three bonds and is valuable for the peak assignments of non-protonated carbons, such as nitrile and carbonyl carbons. In the HMBC spectra the triads of the carbonyl and nitrile region exhibited coupling with the methine, methylene and $\alpha$-methyl region of $\mathrm{A} / \mathrm{M}$ copolymer which were assigned with the help of 2D HSQC and 2D TOCSY.

HMBC spectra in Figure 8 show various couplings between the carbonyl carbon and $\alpha-\mathrm{CH}_{3}$ protons. Figure 8a clearly demonstrates that the region along carbon axis is divided into three parts, i.e., spectral region $173.20-174.61 \mathrm{ppm}, 174.60-176.60 \mathrm{ppm}$ and $176.60-178.72 \mathrm{ppm}$ and was assigned to ABA, BBA and BBB triads respectively. The crosspeaks (1), (2) and (3) were rationalized owing to the coupling between the carbonyl carbon with $\alpha-\mathrm{CH}_{3}$ protons in $\mathrm{BrBrB}, \mathrm{BmBrB}$ and $\mathrm{BmBmB}$ respectively. Carbonyl carbon in BBA also demos three bond coupling with $\alpha-\mathrm{CH}_{3}$ protons in different environment. Consequently, the crosspeaks at (4), and (5) were due to the coupling between the carbonyl carbon and the $\alpha-\mathrm{CH}_{3}$ protons in BBA triad. Three bond couplings were also seen in carbonyl carbon with $\alpha-\mathrm{CH}_{3}$ protons in ABA at (6), (7) and (8). Thus, couplings seen in HMBC also confirmed the assignments of $\alpha-\mathrm{CH}_{3}$ done in HSQC NMR studies. 


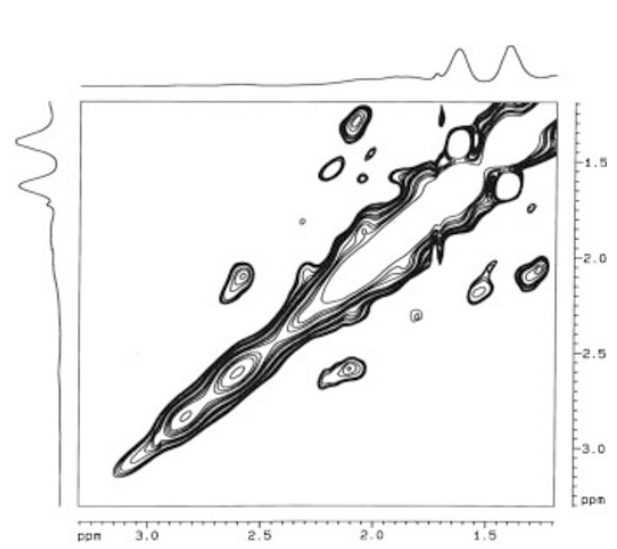

(a)

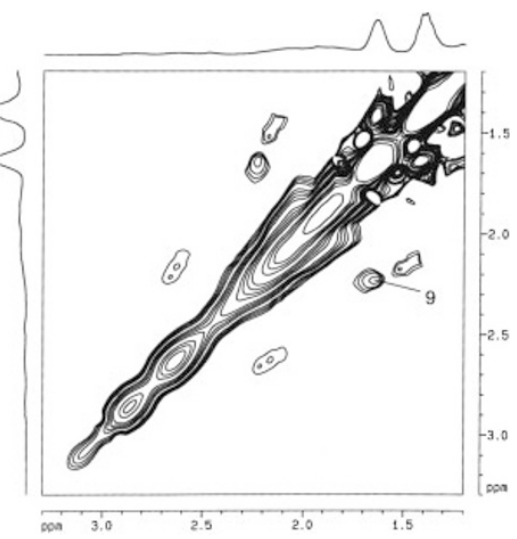

(b)

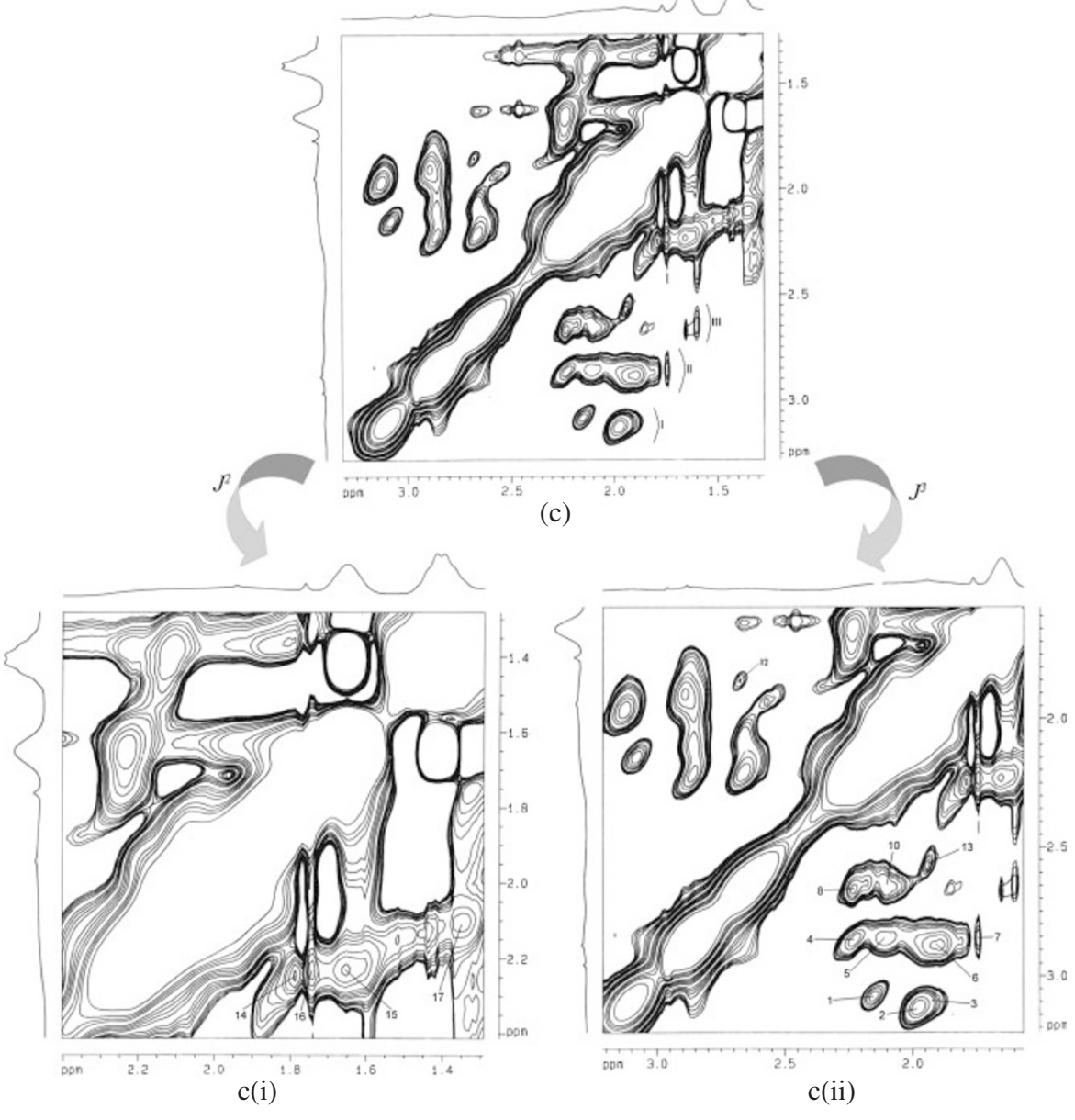

Figure 6. $2 \mathrm{D}$ TOCSY NMR spectra of A/B copolymer in low mixing time (4 ms) having (a) $F_{A}=0.29$, (b) $F_{A}=0.39$ and (c) $\mathrm{F}_{\mathrm{A}}=0.56$.

In addition to couplings between carbonyl carbon and $\alpha-\mathrm{CH}_{3}$ proton, coupling of carbonyl carbon with $\beta$-methylene protons in various tetrad were also seen. These couplings were also figured out from HMBC spectrum shown in Figure 8. The carbonyl region (of BBA triad fraction) $175.10-177.00 \mathrm{ppm}$ along the carbon axis showed association with the $\beta$-methylene protons in BA units. Crosspeak 10 was due to the coupling of carbonyl carbon with the $\beta$-methylene protons in $\mathrm{AArBB} / \mathrm{ABrAB}$ tetrad. While the cross peaks at (9) and (11) were observed due to the three bond coupling between $\beta$-methylene protons $\left(\mathrm{H}_{\mathrm{b}^{\prime}}\right.$ and $\mathrm{H}_{\mathrm{a}^{\prime}}$ ) of $\mathrm{BArBB}$ tetrad. The carbonyl region (BBB triad) $177.00-178.80 \mathrm{ppm}$ along the carbon axis showed multiple bond coupling with $\beta$-methylene protons in BB unit. The carbonyl carbon in BBB triad couple with $\mathrm{H}_{\mathrm{a}}$ of of $\beta$-methylene proton in $\mathrm{ABmBB}$ tetrad resulted in crosspeak at (12). The crosspeaks at (13) and (14) were due to the ${ }^{3} \mathbf{J}$ coupling between carbonyl carbon and $\beta$-methylene protons in $\mathrm{BBrBB}$ and $\mathrm{ABrBB}$ respectively. Assignments are given in tabular form in Table IV. 


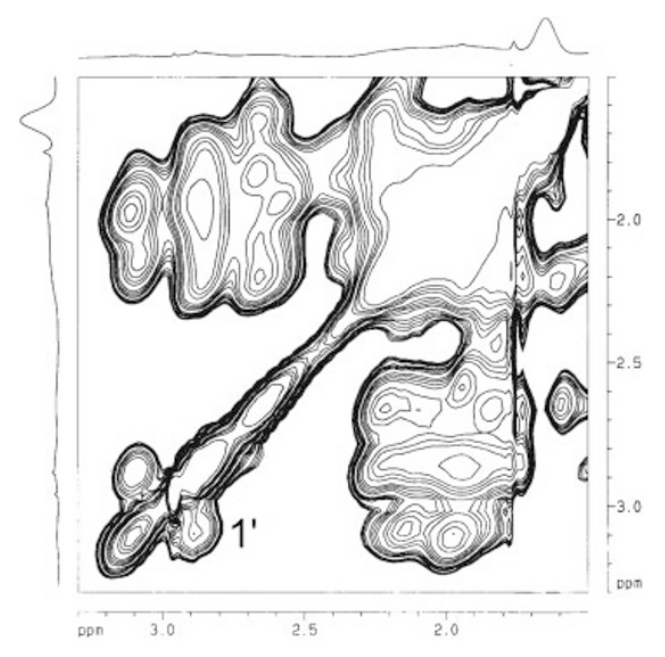

Figure 7. $2 \mathrm{D}$ TOCSY NMR spectra of $\mathrm{A} / \mathrm{B}$ copolymer in high mixing time $(80 \mathrm{~ms})$ having $\mathrm{F}_{\mathrm{A}}=0.56$.

Figure 9 showed multiple bond coupling between the nitrile carbon and the methine as well as $\beta$-methylene protons. Two bond couplings were observed between the nitrile carbon and the methine protons in ArAmA (1) and AmAmA (2) triads. Nitrile carbon also correlated with the $\beta$-methylene protons of $\mathrm{AArAB}$ (3) and $\mathrm{H}_{\mathrm{b}} \beta$-methylene proton in AAmAB (4). $\beta$-methylene proton in AAmAA coupled with the nitrile carbon in AAA triad and gave the crosspeak (5) (Table V).

\section{CONCLUSIONS}

Quantitative ${ }^{13} \mathrm{C}\left\{{ }^{1} \mathrm{H}\right\}$ NMR spectroscopy was used to assess the copolymer composition by quantifying carbonyl and nitrile carbons. The reactivity ratio analysis demonstrated that during radical polymerization butyl methacrylate was more reactive than acrylonitirile. This behavior is analogous to other members of the alkyl methacrylate series. The sequence distribution of acrylonitrile-butyl methacrylate was deliberated with the help of two-dimensional NMR spectroscopy due to unresolved signals in 1D-NMR. $\alpha$-methyl, methine and methylene region depicted sensitivity towards both composition and configuration. These regions were comprehensively analyzed by $2 \mathrm{D}-\mathrm{NMR}$ (HSQC, TOCSY and HMBC) spectroscopy which appropriated ${ }^{\mathrm{n}} \mathbf{J}(\mathrm{n}=1$ (HSQC), 2 and 3 (TOCSY and HMBC)) bond couplings detection. HSQC showed compositional and configurational sensitivity of A, B centered unit of methine and $\alpha$-methyl ${ }^{13} \mathrm{C} /{ }^{1} \mathrm{H}$ region up to the triad and pentad level while methylene region showed sensitivity to the tetrad level. TOCSY demonstrated two and three bond couplings between the protons of different directly coupled groups. HMBC experiment exhibited carbonyl and nitrile car-

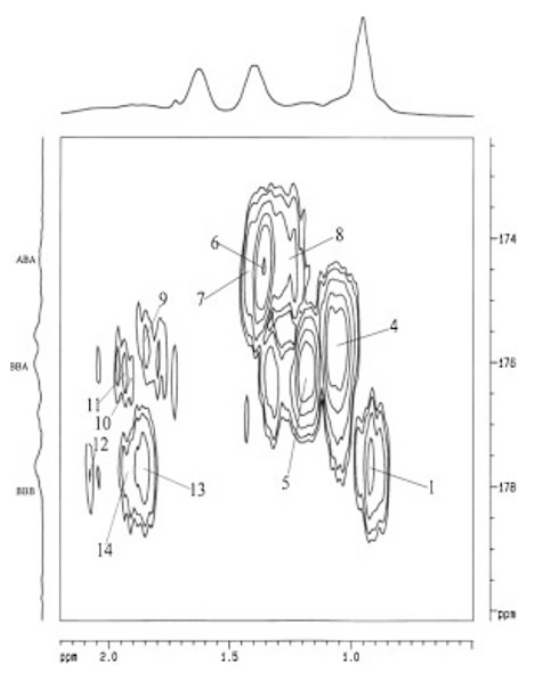

(a)

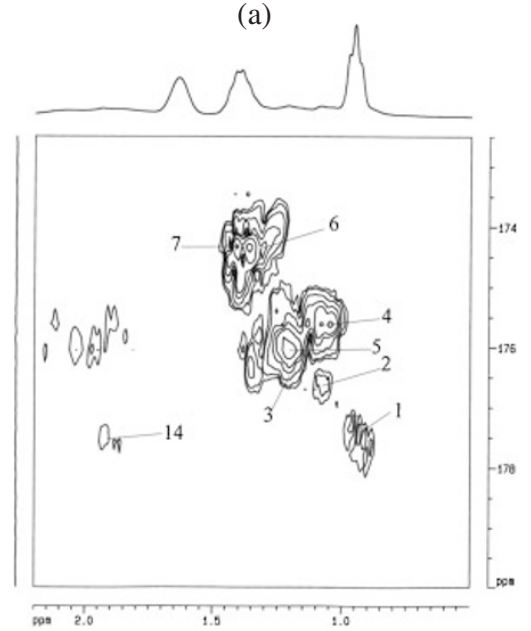

(b)

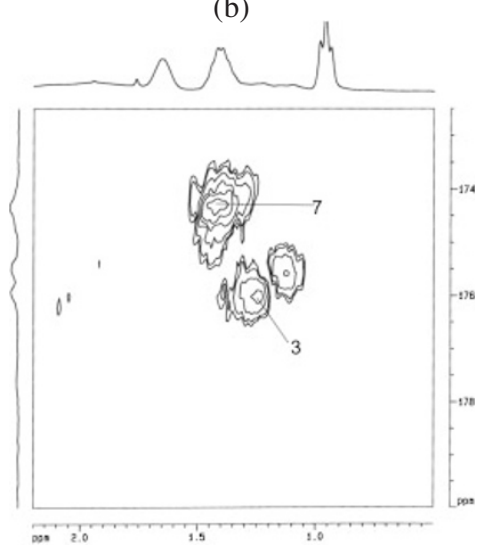

(c)

Figure 8. 2D HMBC NMR spectra of $A / B$ copolymer showing the carbonyl region, having (a) $\mathrm{F}_{\mathrm{A}}=0.29$, (b) $\mathrm{F}_{\mathrm{A}}=0.39$ and (c) $\mathrm{F}_{\mathrm{A}}=0.56$.

bon couplings with the $\alpha$-methyl, methine and methylene protons, HMBC in conjugation with HSQC and TOCSY strongly reaffirmed the assignments.

Acknowledgment. One of the authors (Jaspreet Kaur) acknowledges Council of Scientific and Industrial Research (CSIR), India for the financial support. 
2D-NMR Studies of Butylmethacrylate-Acrylonitrile Copolymers

Table IV. HMBC data showing correlation between carbonyl carbon and proton in acrylonitrile/butyl methacrylate copolymer

\begin{tabular}{|c|c|c|}
\hline S. No. & Type of carbonyl carbon (ppm) & Coupling with (ppm) \\
\hline 1 & $(\mathrm{C}=\mathrm{O})_{\mathrm{B}}$ in $\mathrm{BBB}$ triad $(177.63)$ & $\alpha-\mathrm{CH}_{3}$ in $\mathrm{BrBrB}$ triad $(0.92)$ \\
\hline 2 & $(\mathrm{C}=\mathrm{O})_{\mathrm{B}}$ in $\mathrm{BBB}$ triad $(176.67)$ & $\alpha-\mathrm{CH}_{3}$ in $\mathrm{BmBrB}$ triad (1.06) \\
\hline 3 & $(\mathrm{C}=\mathrm{O})_{\mathrm{B}}$ in $\mathrm{BBB}$ triad $(176.42)$ & $\alpha-\mathrm{CH}_{3}$ in $\mathrm{BmBmB}$ triad (1.24) \\
\hline 4 & $(\mathrm{C}=\mathrm{O})_{\mathrm{B}}$ in $\mathrm{BBA}$ triad $(175.55)$ & $\alpha-\mathrm{CH}_{3}$ in BBA triad (1.09) \\
\hline 5 & $(\mathrm{C}=\mathrm{O})_{\mathrm{B}}$ in $\mathrm{BBA}$ triad $(176.10)$ & $\alpha-\mathrm{CH}_{3}$ in BBA triad (1.18) \\
\hline 6 & $(\mathrm{C}=\mathrm{O})_{\mathrm{B}}$ in $\mathrm{ABA}$ triad $(174.35)$ & $\alpha-\mathrm{CH}_{3}$ in $\mathrm{ABA}$ triad (1.34) \\
\hline 7 & $(\mathrm{C}=\mathrm{O})_{\mathrm{B}}$ in $\mathrm{ABA}$ triad $(174.34)$ & $\alpha-\mathrm{CH}_{3}$ in $\mathrm{ABA}$ triad (1.42) \\
\hline 8 & $(\mathrm{C}=\mathrm{O})_{\mathrm{B}}$ in $\mathrm{ABA}$ triad $(174.22)$ & $\alpha-\mathrm{CH}_{3}$ in $\mathrm{ABA}$ triad (1.24) \\
\hline 9 & $(\mathrm{C}=\mathrm{O})_{\mathrm{B}}$ in $\mathrm{BBA}$ triad $(175.62)$ & $\mathrm{H}_{\mathrm{b}^{\prime}}$ of $\beta-\mathrm{CH}_{2}$ in BArBB tetrad (1.82) \\
\hline 10 & $(\mathrm{C}=\mathrm{O})_{\mathrm{B}}$ in $\mathrm{BBA}$ triad $(176.16)$ & $\beta-\mathrm{CH}_{2}$ in $\mathrm{AArBB} / \mathrm{ABrAB}$ tetrad (1.91) \\
\hline 11 & $(\mathrm{C}=\mathrm{O})_{\mathrm{B}}$ in $\mathrm{BBA}$ triad $(176.04)$ & $\mathrm{H}_{\mathrm{a}^{\prime}}$ of $\beta-\mathrm{CH}_{2}$ in $\mathrm{BArBB}$ tetrad (1.94) \\
\hline 12 & $(\mathrm{C}=\mathrm{O})_{\mathrm{B}}$ in $\mathrm{BBB}$ triad $(177.75)$ & $\mathrm{H}_{\mathrm{a}}$ of $\beta-\mathrm{CH}_{2}$ in $\mathrm{ABmBB}(2.08)$ \\
\hline 13 & $(\mathrm{C}=\mathrm{O})_{\mathrm{B}}$ in $\mathrm{BBB}$ triad $(177.59)$ & $\beta-\mathrm{CH}_{2}$ in $\mathrm{BBrBB}$ tetrad (1.87) \\
\hline 14 & $(\mathrm{C}=\mathrm{O})_{\mathrm{B}}$ in $\mathrm{BBB}$ triad $(177.72)$ & $\beta-\mathrm{CH}_{2}$ in $\mathrm{ABrBB}$ tetrad (1.93) \\
\hline
\end{tabular}

Table V. HMBC data showing correlation between nitrile carbon and proton in acrylonitrile/butyl methacrylate copolymer

\begin{tabular}{cll}
\hline S. No. & Type of nitrile carbon $(\mathrm{ppm})$ & \multicolumn{1}{c}{ Coupling with (ppm) } \\
\hline 1 & $(\mathrm{CN})_{\mathrm{A}}$ in AAA triad (119.96) & $\mathrm{CH}$ in AAA triad (3.11) \\
2 & $(\mathrm{CN})_{\mathrm{A}}$ in AAA triad (120.19) & $\mathrm{CH}$ in AAA triad (3.07) \\
3 & $(\mathrm{CN})_{\mathrm{A}}$ in AAA triad $(120.41)$ & $\beta-\mathrm{CH}_{2}$ in AArAB tetrad (2.08) \\
4 & $(\mathrm{CN})_{\mathrm{A}}$ in AAA triad $(120.09)$ & $\mathrm{H}_{\mathrm{b}}$ of $\beta-\mathrm{CH}_{2}$ in AAmAB tetrad (1.95) \\
5 & $(\mathrm{CN})_{\mathrm{A}}$ in AAA triad $(120.07)$ & $\beta-\mathrm{CH}_{2}$ in AAAA tetrad (1.93) \\
\hline
\end{tabular}

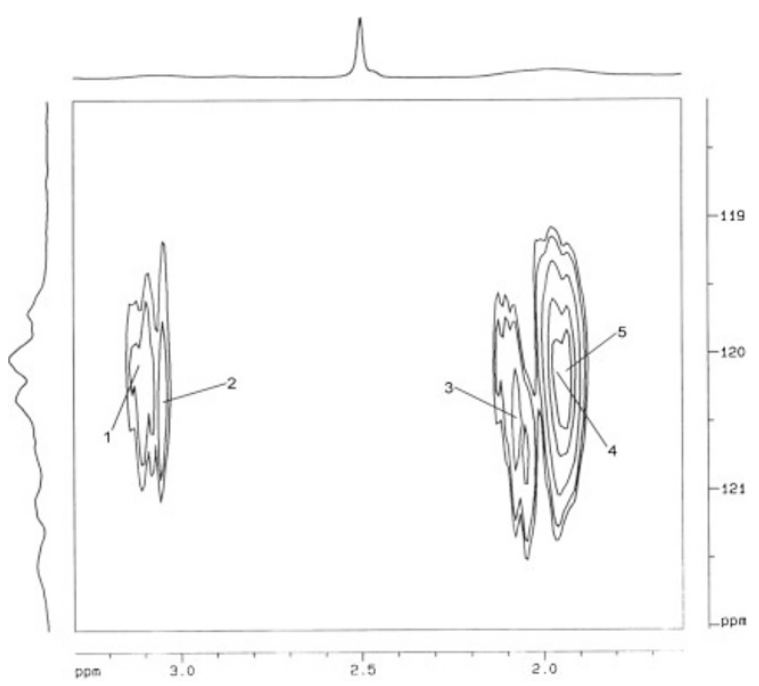

Figure 9. 2D HMBC NMR spectra of A/B copolymer showing the nitrile region, having $\mathrm{F}_{\mathrm{A}}=0.79$.

\section{REFERENCES}

1. D. A. Tirrell, in, "Encyclopedia of Polymer Science and Engineering," 2nd ed., H. Mark, N. M. Bikales, C. G. Overberger, and G. Menges, Ed., John Wiley \& Sons, New York, 1985, Vol. 4.

2. J. P. Montheard, M. Chatzopoulos, and D. Chappard,
J. Macromol. Sci., Rev. Macromol. Chem. Phys., C32, 1 (1992).

3. B. Weightman, M. A. R. Freeman, P. A. Revell, M. Braden, B. E. J. Albrektsson, and L. V. Carlson, J. Bone Joint Surg. (Br), 69, 558 (1987).

4. K. M. F. Ahlberg and W. M. Tay, Inter. Endo. J., 31, 15 (1998).

5. N. A. Peppas and J. J. Sahlin, Biomaterials, 17, 1553 (1996).

6. A. Chenite, C. Chaput, D. Wang, C. Combes, M. D. Buschmann, C. D. Hoemann, J. C. Leroux, B. L. Atkinson, F. Binette, and A. Selmani, Biomaterials, 21, 2155 (2000).

7. D. J. T. Hill, N. G. Moss, P. J. Pomery, and A. K. Whittaker, Polymer, 41, 1287 (2000).

8. Y. Li, M. J. Yang, and Y. She, Sens. Actuators, B, 107, 252 (2005).

9. K. Shimozawa, M. Saito, and R. Chujo, ACS Symposium Series No. 208, 2003.

10. K. Matsuzaki, T. Uryu and T. Asakura, "NMR Spectroscopy and Stereoregularity of Polymers," Japan Scientific Societies Press, Tokyo, 1996, Chap. 4.

11. G. B. Galland, L. P. D. Silva, M. L. Dias, G. L. Crossetti, C. M. Ziglio, and C. A. L. Filgueiras, J. Polym. Sci., Part A: Polym. Chem., 42, 2171 (2004).

12. K. B. Wiles, V. A. Bhanu, A. J. Pasquale, T. E. Long, and J. E. McGrath, J. Polym. Sci., Part A: Polym. Chem., 42, 2994 (2004).

13. H. Ito and D. C. Miller, J. Polym. Sci., Part A: Polym. Chem., 42, 1468 (2004).

14. H. S. Bisht, S. S. Ray, and A. K. Chatterjee, J. Polym. Sci., Part A: Polym. Chem., 41, 1864 (2003). 
15. H. N. Cheng, J. Appl. Polym. Sci., 43, 129 (1989).

16. "NMR Spectroscopy of Polymers in Solution and in Solid State," H. N. Cheng and A. D. English, Ed., ACS Symposium Series, No. 834, American Chemical Society, 2003.

17. E. Y. Chen, J. Polym. Sci., Part A: Polym. Chem., 42, 3395 (2004).

18. Y. Kim and H. J. Harwood, Polymer, 43, 3229 (2002).

19. J. Spevacek, M. Suchoparek, and S. A. Alawi, Polymer, 36, 4125 (1995).

20. J. J. Kotyk, P. A. Berger, and E. E. Ramson, Macromolecules, 23, 5167 (1990).

21. L. Dond, D. J. T. Hill, J. H. O'Donell, and A. K. Whittaker, Macromolecules, 27, 1830 (1994).

22. K. Hatada, T. Kitayama, Y. Terawaki, H. Sato, R. Chujo, Y. Tanaka, R. Kitamaru, I. Ando, K. Hikichi, and F. Horii, Polym. J., 27, 1104 (1995).

23. L. Weixia, P. L. Rinaldi, L. H. McIntosh, and P. R. Roderic, Macromolecules, 34, 4757 (2001).

24. S. J. Oh, D. R. Kinney, W. Wang, and P. L. Rinaldi, Macromolecules, 35, 2602 (2002).

25. F. J. Wyzgoski, P. L. Rinaldi, E. F. McCord, M. A. Stewart, and D. R. Marshall, Macromolecules, 37, 846 (2004).

26. X. Xie, M. Wittmar, and T. Kissel, Macromolecules, 37, 4598 (2004).

27. M. Suchoparek and J. Spevacek, Macromolecules, 26, 102 (1993).

28. L. Dong, D. J. T. Hill, J. H. O'Donnell, and A. K. Whittaker, Macromolecules, 27, 1830 (1994).

29. A. S. Brar and M. Malhotra, Macromolecules, 29, 7040 (1996).

30. N. Nakayama, A. Akoi, and T. Hayashi, Macromolecules, 27, 63 (1994).

31. T. Asakura, N. Nakayama, M. Demura, and A. Asano, Macromolecules, 25, 4876 (1992).

32. A. Kowalczuk-Bleja, B. Trzebicka, H. Komber, B. Voit, and A. Dworak, Polymer, 45, 9 (2004).

33. H. Matsuda, B. Nagasaka, and T. Asakura, Polymer, 44, 4681 (2003).

34. U. Subramanyam, P. R. Rajamohanan, and S. Sivaram, Polymer, 45, 4063 (2004).
35. A. S. Brar, S. Hooda, and R. Kumar, J. Polym. Sci., Part A: Polym. Chem., 41, 13 (2003).

36. A. S. Brar and D. R. Pradhan, J. Appl. Polym. Sci., 89, 1779 (2003).

37. A. S. Brar, in "NMR Spectroscopy of Polymers in Solution and in Solid State," H. N. Cheng and A. D. English, Ed., ACS Symposium Series, No. 834, American Chemical Society, 2003, p. 166.

38. A. S. Brar, Polym. Prepr. (Am. Chem. Soc., Div. Polym. Chem.), 42, 11 (2001).

39. A. S. Brar, Abstracts of Papers, 221st ACS National Meeting, San Diego, CA, United States, April 1-5, 2001.

40. A. S. Brar and S. K. Hekmatyar, J. Appl. Polym. Sci., 74, 3026 (1999).

41. A. S. Brar and K. Dutta, Macromol. Chem. Phys., 199, 2005 (1998).

42. A. S. Brar and K. Dutta, J. Appl. Polym. Sci., 69, 2507 (1998).

43. A. S. Brar and K. Dutta, Macromolecules, 31, 4695 (1998).

44. A. S. Brar, K. Dutta, and S. K. Hekmatyar, J. Polym. Sci., Part A: Polym. Chem., 36, 1081 (1998).

45. A. S. Brar, B. Jayaram, and K. Dutta, J. Polym. Mater., 11, 171 (1994).

46. G. S. Kapur and A. S. Brar, Makromol. Chem., 192, 2733 (1991).

47. G. S. Kapur and A. S. Brar, Polymer, 32, 1112 (1991).

48. G. S. Kapur and A. S. Brar, J. Polym. Sci., Part A: Polym. Chem., 29, 479 (1991).

49. A. S. Brar and S. K. Dubey, Indian J. Chem., Sect. A: Inorg., Bio-inorg., Phys., Theor. Anal. Chem., 28A, 570 (1989).

50. Pham-Quang-Tho and J. Guillot, J. Polym. Sci., Polym. Chem. Ed., 8, 2893 (1970).

51. S. D. Yeo and E. Kiran, Macromolecules, 37, 8239 (2004).

52. A. S. Brar and J. Kaur, Eur. Polym. J., 41, 2278 (2005).

53. R. Z. Greenley, J. Macromol. Sci.-Chem., A14, 445 (1980).

54. A. S. Nair and M. S. Muthana, Makromol. Chem., 47, 128 (1961).

55. K. Matsuzaki, T. Uryu, and T. Asakura, "NMR Spectroscopy and Stereoregularity of Polymers," Japan Scientific Societies Press, Tokyo, 1996, Chap. 10. 